\title{
The Gastroenterology Fellowship Match: A Decade Later
}

\author{
Robert J. Huang ${ }^{1} \cdot$ George Triadafilopoulos $^{1} \cdot$ David Limsui $^{1}$
}

Received: 10 February 2017/ Accepted: 25 April 2017/Published online: 4 May 2017

(C) Springer Science+Business Media New York 2017

\begin{abstract}
Following a period of uncertainty and disorganization, the gastroenterology (GI) national leadership decided to reinstitute the fellowship match (the Match) under the auspices of the National Residency Matching Program (NRMP) in 2006. Although it has now been a decade since the rebirth of the Match, there have been limited data published regarding progress made. In this piece, we discuss reasons for the original collapse of the GI Match, including most notably a perceived oversupply of GI physicians and a poor job market. We discuss the negative impacts the absence of the Match had on programs and on applicants, as well as the impetus to reorganize the Match under the NRMP. We then utilize data published annually by the NRMP to demonstrate that in the decade since its rebirth, the GI Match has been remarkably successful in terms of attracting the participation of applicants and programs. We show that previous misguided concerns of an oversupply of GI physicians were not realized, and that GI fellowship positions remain highly competitive for internal medicine applicants. Finally, we discuss possible implications of recent changes in the healthcare landscape on the GI Match.
\end{abstract}

Keywords Gastroenterology · Fellowship · Match · National Residency Matching Program · Job market . Affordable Care Act

Robert J. Huang

rjhuang@stanford.edu

1 Division of Gastroenterology and Hepatology, Stanford University Medical Center, Alway Building, Room M211, 300 Pasteur Drive, MC: 5187, Stanford, CA 94305-5187, USA

$\begin{array}{ll}\text { Abbreviations } \\ \text { GI } & \text { Gastroenterology } \\ \text { US } & \text { United States } \\ \text { Match } & \text { Matching program } \\ \text { NRMP } & \text { National Residency Matching Program } \\ \text { ACGME } & \text { Accreditation Council for Graduate Medical } \\ & \text { Education } \\ \text { AGA } & \text { American Gastroenterological Association } \\ \text { TAPP } & \text { Total applicants per position } \\ \text { USAPP } & \text { US allopathic medical school graduate } \\ & \text { applicants per position } \\ \text { USMR } & \text { US graduate successful match rate } \\ \text { CV } & \text { Cardiovascular Disease } \\ \text { Endo } & \text { Endocrinology } \\ \text { HO } & \text { Hematology and Oncology } \\ \text { ID } & \text { Infectious Disease } \\ \text { Neph } & \text { Nephrology } \\ \text { PulmCC } & \text { Pulmonary Disease and Critical Care Medicine } \\ \text { Rheum } & \text { Rheumatology } \\ \text { GIM } & \text { General Internal Medicine }\end{array}$

\section{Introduction}

In 2006, almost all gastroenterology (GI) fellowship training programs in the United States (US) accredited by the Accreditation Council for Graduate Medical Education (ACGME) officially rejoined the matching program (Match) organized under the National Resident Matching Program (NRMP). This event brought to an end a disorderly period characterized by decentralized application, interview, and offer processes. We offer historical perspective on the importance of this seminal event to both GI fellowship applicants and training programs, and discuss recent trends based on data obtained from the NRMP. 


\section{History of Application to Gastroenterology Fellowships}

Prior to 1986, internal medicine residents applied and interviewed for GI fellowships in a piecemeal, decentralized process, characterized by disorderly procedures that at times bordered on chaos. In response to this situation, GI and other internal medicine fellowship programs organized into a centralized Match through the NRMP. The GI Match operated well, with high participation rates by programs, and a surplus of applicants relative to available positions [1].

\section{Collapse of the Original Match}

In the early 1990s, in the midst of calls for national healthcare reform, there surfaced a concern for a perceived oversupply of specialists in an era of unrealistic (in retrospect) reliance on primary care as a solution to escalating costs. As a result, in 1996 the GI Leadership Council endorsed a goal of a $25-50 \%$ reduction in trainee members over 5 years, as well as an increase in fellowship length from 2 to 3 years [2]. The number of GI fellowship positions offered through the Match was substantially reduced beginning in 1996; however, this policy decision led to the unexpected consequence of reducing the number of GI fellowship applicants even more precipitously than the number of available positions [3]. Perhaps seeing "the writing on the wall," a survey of internal medicine residents in 2000 revealed that fewer than $10 \%$ were interested in GI, mainly due to the perception of a poor job market [4]. Whereas historically, GI had always enjoyed a surplus of applicants relative to available positions, the number of positions actually exceeded the number of applicants in 1996 [3]. As a result of the dwindling number of applicants and positions, GI formally withdrew from the Match in the year 2000.

\section{Rebirth of the Match}

The absence of a centralized Match led to several deleterious effects for both applicants and programs. In an effort to secure recruitment of the best out of a dwindling supply of applicants, programs began to offer interviews earlier, often more than 18 months prior to the actual starting date for new fellows [3]. Moreover, multiple offers would sometimes occur over a short period, forcing applicants to make decisions within weeks or even days of an offer [5]. The absence of a Match also substantially decreased trainee mobility, as fellows increasingly relied on staying at their home institution due to environmental uncertainty [3]. Due in part to these onerous effects on applicants, and also due in part to the easing of fears of an oversupply of gastroenterologists, increasingly vociferous calls were made to reintroduce a GI fellowship Match.

In 2004, the American Gastroenterological Association (AGA) convened a taskforce of academic leaders, which recommended the reinstitution of a Match following consultation with division chiefs, program directors, and the leadership of the AGA and of other major national GI societies [6]. With a threshold of $75 \%$ of GI fellowship programs committing to rejoining the NRMP, the new Match opened in January 2006, for positions beginning on July 1, 2007 [6]. Nonetheless, since the reinstitution of the GI fellowship Match, there has been limited data published regarding Match statistics and progress.

\section{Current Status of the Match}

Through analysis of the data published yearly by the NRMP, we sought to determine whether current program and applicant interest in GI fellowships remains strong [7]. Figure 1 shows trends across time (by fellowship appointment year) in the number of applicants, number of positions, and total number of programs participating in the Match since 2008. While both the number of applicants and number of positions increased, the relative increase in positions $(+43 \%)$ was greater than the increase in applicants $(+15 \%)$. The increase in positions was also greater than the increase in number of participating programs $(+19 \%)$, suggesting that at least some fellowship programs have increased the number of fellows accepted.

We also sought to compare trends in applicants and positions for GI with the other major subspecialties within internal medicine that participate in the NRMP: Cardiovascular Disease (CV), Endocrinology (Endo), Hematology and Oncology (HO), Infectious Disease (ID),

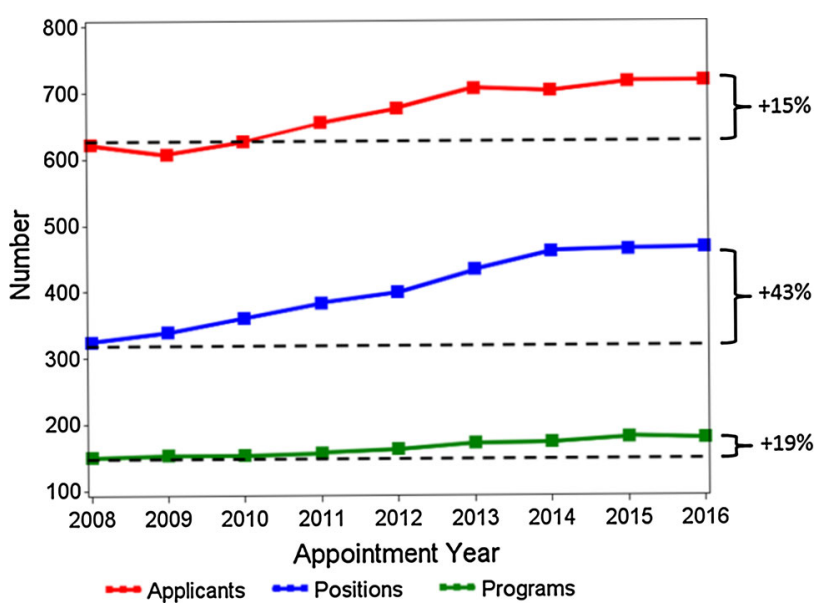

Fig. 1 Number of applicants, positions, and programs participating in the gastroenterology fellowship match by appointment year 
Nephrology (Neph), Pulmonary Disease and Critical Care Medicine (PulmCC), and Rheumatology (Rheum). To compare across time and across specialties, we used a number of markers that previously have been used as surrogates for specialty competitiveness, namely the number of total applicants per position (TAPP) [8], the number of US allopathic medical school graduate applicants per position (USAPP) $[8,9]$, and the US graduate successful match rate (USMR) [10]. Generally speaking, more competitive specialties tend to have higher TAPP and USAPP ratios and lower USMRs, as there are more applicants relative to the number of available positions.

By all three metrics, GI was and remains the most competitive subspecialty following internal medicine residency. Throughout the period from 2008 to 2016, GI consistently demonstrated the highest TAPP (Fig. 2a), the highest USAPP (Fig. 2b), and the lowest USMR (Fig. 2c) for all subspecialties of internal medicine. Notably, however, all subspecialties including GI demonstrated a trend toward lower TAPP, lower USAPP, and higher USMR over time, suggesting that since 2008, fewer internal medicine
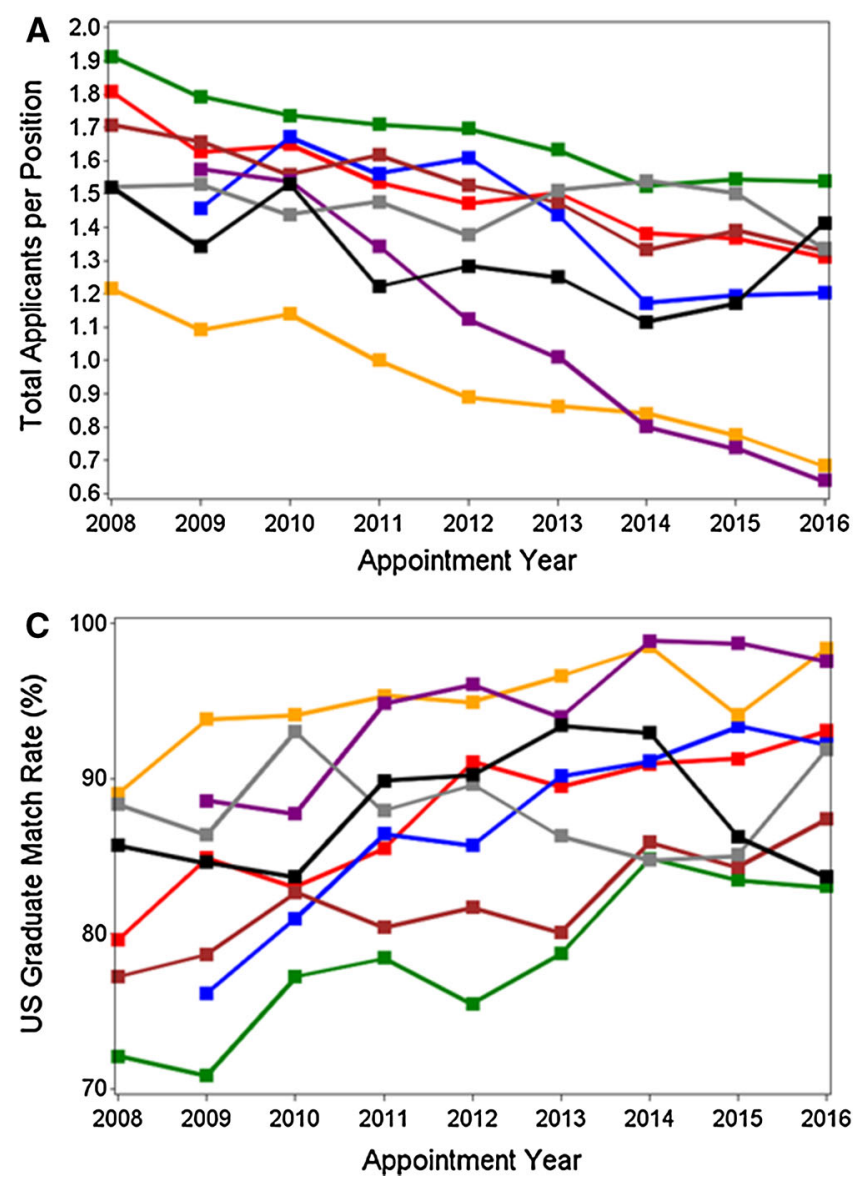

Fig. 2 Trends by year for fellowship matches in Cardiovascular Disease $(\mathrm{CV})$, Endocrine, Diabetes, and Metabolism (Endo), Gastroenterology $(G I)$, Hematology and Oncology $(H O)$, Infectious Disease (ID), Nephrology (Neph), Pulmonary Disease and Critical residents as a whole have chosen to enter subspecialty training.

We sought to compare recent trends in physician compensation by specialty since the passage of the Affordable Care Act (ACA) in 2010, as one aim of the new law was to lessen the income disparities between primary and specialty physicians [11]. Figure 3 shows trends in mean annual physician compensation for the subspecialties of internal medicine as well as general internal medicine (GIM) for the years 2011-2015, utilizing annual survey data published by Medscape (WebMD, New York, NY) [12]. There has been little shift in specialty compensation over this period. The highest compensated specialties in 2011 (CV and GI) remained the highest compensated specialties in 2015 (CV $\$ 410 \mathrm{~K}, \mathrm{GI} \$ 380 \mathrm{~K}$ ). The lowest compensated specialties in 2011 (Endo, ID, and Rheum) remained the lowest compensated specialties in 2015 (Endo \$206 K, ID \$215 K, Rheum \$234 K). GIM compensation increased significantly over the period, from $\$ 166 \mathrm{~K}$ in 2011 to $\$ 222 \mathrm{~K}$ in 2015 ; yet, as compensation
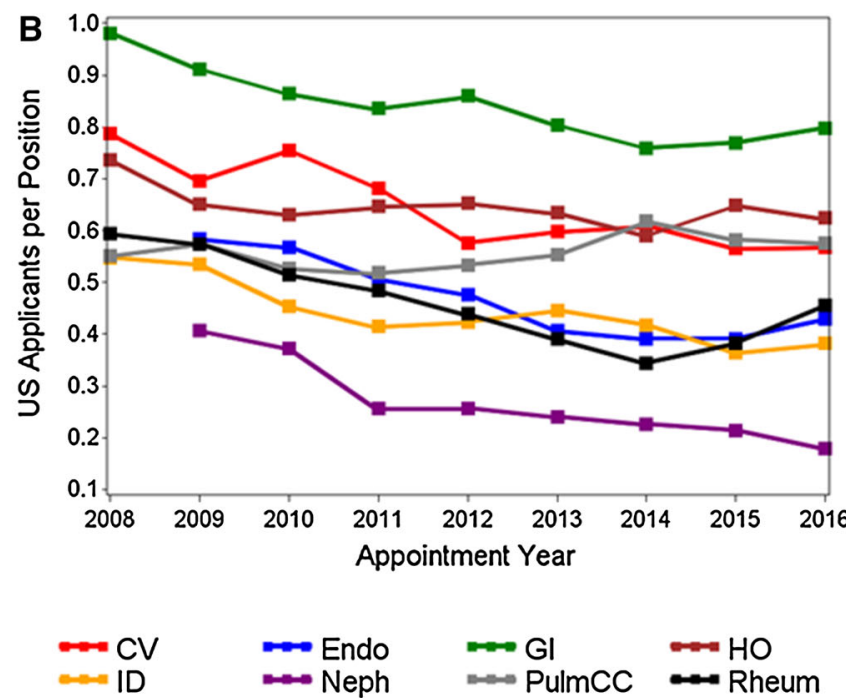

Care Medicine (PulmCC), and Rheumatology (Rheum) by total applicants per position (a), US allopathic medical school graduate applicants per position (b), and US graduate match rate (c) 


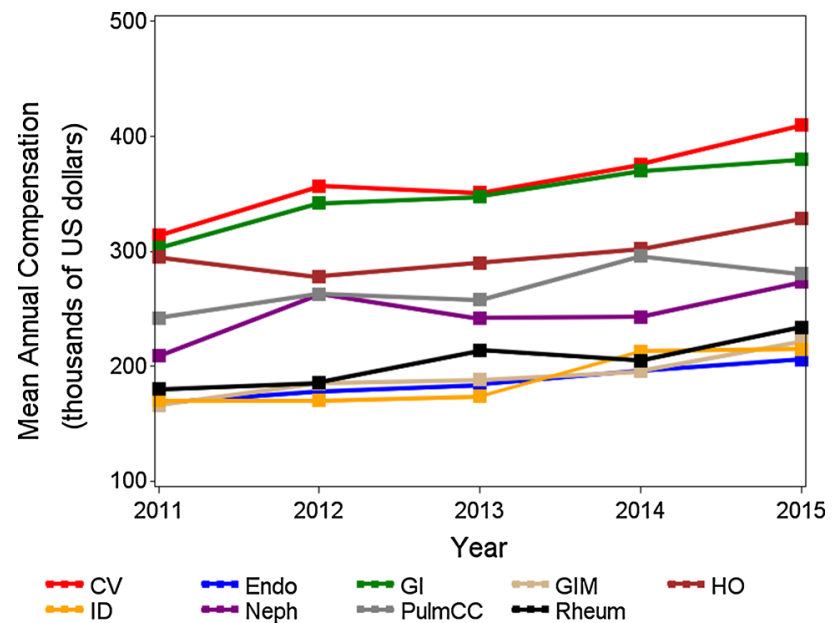

Fig. 3 Mean annual patient-care compensation of physicians in Cardiovascular Disease $(\mathrm{CV})$, Endocrine, Diabetes, and Metabolism (Endo), Gastroenterology (GI), General Internal Medicine (GIM), Hematology and Oncology $(H O)$, Infectious Disease (ID), Nephrology (Neph), Pulmonary Disease and Critical Care Medicine (PulmCC), and Rheumatology (Rheum) by year

rose across all specialties, GIM remained among the lowest compensated fields.

\section{Discussion and Future Trends}

Based on these NRMP data, overall program participation in the Match remains strong. The total number of participating programs has increased since 2008. Part of this increase may be preexisting "hold-out" GI training programs joining the Match, and part of this might be due to the creation of new GI training programs. Fellowship size is also expanding, as the number of positions has grown more quickly than the number of programs. Clearly, the concerns for an oversupply of gastroenterologists from an earlier era have receded, and the ongoing expansion of GI training programs is perhaps a sign of confidence by GI divisions around the country in a strong and growing market for gastroenterologists. From the applicants' perspective, GI remains a competitive and desirable field. As judged by TAPP, USAPP, and USMR, GI arguably has been and remains the most competitive fellowship to enter among the subspecialty fellowships of internal medicine. While the choice of a specialty is a complex and individualized process, expected future earning potential has a direct and highly correlative relationship with specialty competitiveness [13]. The relatively attractive remuneration of GI compared to other fields doubtless contributes to its ongoing attractiveness to applicants.

While the passage of the ACA has yet to meaningfully lessen the income disparity between generalists and specialists, other facets of the new law may be encouraging more medical students and residents away from subspecialization. The ACA contains multiple provisions to incentivize medical students to pursue careers in primary care including loan forgiveness, investment in resources used to recruit primary care clinicians to underserved areas, and enhanced funding of primary care-focused training programs [14]. This increased emphasis on primary care, as well as the rapid growth of professional hospitalists in the US [15], may explain the overall decrease in interest in subspecialty training seen in our data.

In conclusion, one decade after the rebirth of the Match, GI fellowship training programs find themselves in a healthy and stable position. Program participation in the Match remains high, with steady increases in the number of applicants and in available positions. GI as a specialty also remains a desirable destination for many internal medicine residents, even in the face of a changing US healthcare landscape.

\section{Compliance with ethical standards}

Conflict of interest The authors have no financial, professional, or personal conflicts of interest to disclose.

\section{References}

1. Niederle M, Roth AE. Unraveling reduces mobility in a labor market: gastroenterology with and without a centralized match. $J$ Polit Econ. 2003;111:1342-1352.

2. Meyer GS, Jacoby I, Krakauer H, Powell DW, Aurand J, McCardle P. Gastroenterology workforce modeling. JAMA. 1996;276:689-694.

3. Niederle M, Roth AE. The gastroenterology fellowship Match: how it failed and why it could succeed once again. Gastroenterology. 2004;127:658-666.

4. Benya RV. Why are internal medicine residents at university medical centers not pursuing fellowship training in gastroenterology? A survey analysis. Am $J$ Gastroenterol. 2000;95:777-783.

5. Pardi DS. Should the national GI fellowship matching program be restored? Am J Gastroenterol. 2004;99:1411-1412.

6. Proctor DD. Gastroenterology fellowship programs rejoin the match. Gastroenterology. 2005;129:780-781.

7. National Resident Matching Program, Results and Data: Specialties Matching Service 2008-2016 Appointment Year. National Resident Matching Program; 2008-2016.

8. Karnes JM, Mayerson JL, Scharschmidt TJ. Is orthopedics more competitive today than when my attending matched? An analysis of National Resident Matching Program data for orthopedic PGY1 applicants from 1984 to 2011. J Surg Educ. 2014;71:530-542.

9. Chen JY, Heller MT. How competitive is the match for radiology residency? Present view and historical perspective. J Am Coll Radiol. 2014;11:501-506.

10. Andriole D, Ryan K, Haire-Joshu D. A comparison of the overall NRMP match results with the results for 19 specialties for senior U.S. medical students, 1996. Acad Med. 1997;72:801-803. 
11. Davis K, Abrams M, Stremikis K. How the Affordable Care Act will strengthen the nation's primary care foundation. J Gen Intern Med. 2011;26:1201-1203.

12. Peckham C. Medscape physician compensation reports, 2012-2016. http://www.medscape.com/. Accessed 1 February, 2017.

13. Ebell MH. Future salary and US residency fill rate revisited. JAMA. 2008;300:1131-1132.
14. Klink K. Incentives for physicians to pursue primary care in the ACA Era AMA. J Ethics. 2015;17:637-646.

15. Kuo YF, Sharma G, Freeman JL, Goodwin JS. Growth in the care of older patients by hospitalists in the United States. $N$ Engl $J$ Med. 2009;360:1102-1112. 